\title{
Intrapleural topical application of cisplatin with the surgical carrier Vivostat increases the local drug concentration in an immune-competent rat model with malignant pleuromesothelioma
}

\author{
D. Lardinois, MD, ${ }^{a}$ F. J. Jung, MD, ${ }^{a}$ I. Opitz, MD, ${ }^{a}$ K. Rentsch, MD, ${ }^{b}$ C. Latkoczy, MD, ${ }^{c}$ V. Vuong, PhD, ${ }^{d}$ Z. Varga, MD, ${ }^{e}$ \\ V. Rousson, PhD, ${ }^{f}$ D. Günther, MD, ${ }^{c}$ S. Bodis, MD, ${ }^{d}$ R. Stahel, MD, ${ }^{g}$ and W. Weder, MDa
}

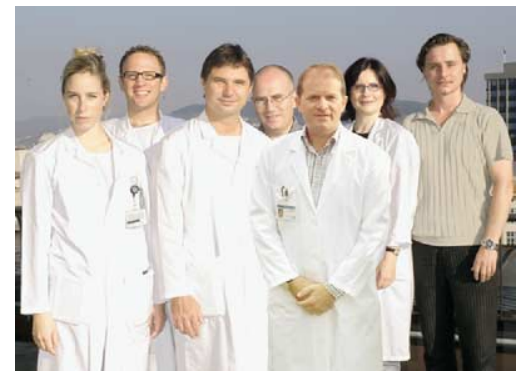

I. Opitz, F.J. Jung, D. Lardinois, M. Pruschy, W. Weder, Z. Varga, C. Latkoczy (left to right)

Supplemental material available online.
Objective: We sought to investigate whether intrapleural topical application of cisplatin with a surgical carrier has a prolonged local tissue level in comparison with cisplatin solution while reducing systemic toxicity.

Methods: Forty immune-competent Fischer rats were inoculated with $10^{6}$ mesothelioma cells. Ten days later, left pneumonectomy with tumor debulking was performed. Twenty animals underwent local application of cisplatin solution (100 $\mathrm{mg} / \mathrm{m}^{2}$ ), whereas the same quantity of cisplatin was topically applied as a gel with the Vivostat (Vivolution) system in 20 other animals. In each group 5 subgroups of 4 animals were defined according to the harvesting time of blood and tissue samples $(2,4,24$, and 72 hours and 1 week) after local therapy. Platinum concentrations in serum and tissue and systemic toxicity were analyzed.

Results: Platinum concentrations in tissue were significantly higher in the gel group (group 1) than in the solution group (group 2) at 1, 3, and 7 days after therapy (1510, 1224 , and $1069 \mathrm{pg} / \mathrm{mg}$ for group 1 vs 598, 382, and $287 \mathrm{pg} / \mathrm{mg}$ for group $2 ; P=$ $.007, P=.005$, and $P=.0002$, respectively). Laboratory findings showed renal insufficiency in the animals of the solution group at 1 week, with values of 98 $\mathrm{mmol} / \mathrm{L}$ versus $7.7 \mathrm{mmol} / \mathrm{L}$ for urea and $410 \mu \mathrm{mol} / \mathrm{L}$ versus $43 \mu \mathrm{mol} / \mathrm{L}$ for creatinine $(P=.02$ and $P=.01$, respectively), which was confirmed by means of pathologic analysis.

Conclusions: Intrapleural administration of cisplatin with the carrier Vivostat significantly provides sustained higher platinum concentrations up to 1 week in tissue in comparison with application of cisplatin solution without conferring systemic toxicity in this model. partment of Radiation Oncology, ${ }^{\mathrm{d}}$ the Institute of Clinical Pathology, ${ }^{\mathrm{e}}$ the Institute of Biostatistics, ${ }^{\mathrm{f}}$ and the Division of Oncology, ${ }^{\mathrm{g}}$ University Hospital, Zurich, Switzerland, and the Laboratory of Inorganic Chemistry, ${ }^{\mathrm{c}}$ ETH, Zurich, Switzerland.

Supported in part by the Swiss Cancer League Zurich and by the Hartmann-Müller Foundation.

Received for publication June 2, 2005; revisions received Aug 5, 2005; accepted for publication Aug 17, 2005.

Address for reprints: D. Lardinois, MD, Division of Thoracic Surgery, University Hospital, Raemistrasse 100, 8091 Zurich, Switzerland (E-mail: didier.lardinois@usz.ch).

J Thorac Cardiovasc Surg 2006;131:697-703

$0022-5223 / \$ 32.00$

Copyright (C) 2006 by The American Association for Thoracic Surgery

doi:10.1016/j.jtcvs.2005.08.012
$\mathrm{M}$ alignant pleural mesothelioma is increasingly observed in industrial countries. Patients with pleural mesothelioma often succumb to the complications of advanced local disease. ${ }^{1,2}$ Therefore treatment strategies often involve aggressive surgical resection. ${ }^{3,4}$ However, even with a multimodal treatment concept, including extrapleural pneumonectomy combined with chemotherapy and radiotherapy, local recurrence is common. ${ }^{1,5}$ Recent publications have demonstrated an improved response rate with the cytostatic agent pemetrexed (Alimta, Lilly), which will be tested in a neoadjuvant setting, followed by surgical intervention. ${ }^{6}$ However, increased local control of microscopic residual disease, which might markedly improve survival, requires novel therapeutic approaches. ${ }^{3,4,7}$ Malignant pleural mesothelioma is an ideal model for testing new locoregional multimodality treatment approaches because of its aggressive local behavior. ${ }^{8}$ Because systemic chemotherapy has had little success in mesothelioma, direct intrapleural delivery has been performed 


\section{Abbreviations and Acronyms \\ PAS $=$ periodic acid-Schiff}

with the rationale of achieving high local drug concentrations while minimizing systemic toxicity. ${ }^{5,7-9}$ Platinum has been more extensively studied for intracavitary use in animals and patients than other modes of local therapy, such as photodynamic therapy or radiotherapy, and will probably remain one of the keys in the chemotherapeutic approach for malignant mesothelioma. ${ }^{10-12}$ To date, platinum is still used for induction chemotherapy in the majority of the multimodality treatment protocols in most experienced centers. Local application of cisplatin (Platinol, Bristol-Myers Squibb) has already been performed intraperitoneally in ovarian carcinoma and intrapleurally in malignant mesothelioma in animal models and in patients at a dose between 80 and $150 \mathrm{mg} / \mathrm{m}^{2}{ }^{5,7-9,13-16}$ It was demonstrated that cisplatin given at high doses is active in mesothelioma, but the response duration was short, possibly because of a lack of effective maintenance of therapy., 5,13

The aim of this study was to investigate whether local topical intrapleural application of cisplatin with the aid of surgical autologous fibrin sealant (Vivostat, Vivolution) has a prolonged local pharmacologic tissue level in comparison with local administration without sealant while reducing systemic drug exposure in an immune-competent rat model.

\section{Methods}

\section{Animal Model and Mesothelioma Cells}

The study protocol was approved by our institution's committee on investigations involving animal subjects. Animal care was provided in accordance with the "Guide for the Care and Use of Laboratory Animals" (National Institutes of Health publication no. 86-23, revised 1985).

The animal model used in this experiment has been previously described. ${ }^{17,18}$ Immune-competent Fischer rats (Harlan) were inoculated with a syngeneic malignant mesothelioma cell line (II-45; cells cultured from experimental asbestos-induced peritoneal mesothelioma in rats, Research Laboratory, UT MD Anderson Cancer Center, Smithville, Tex). Pleural mesothelioma in this model resembled the disease in patients histologically (malignant cells predominantly epithelioid) and was highly reproducible (untreated animal dying within 4 weeks). ${ }^{17}$ Preliminarily, a proliferation assay using the II-45 mesothelioma cells was performed to determine the activity of different concentrations of cisplatin on a seeding of 750 cells per well. A concentration of $1 \mu \mathrm{mol} / \mathrm{L}$ ( 300 $\mu \mathrm{g} / \mathrm{L}$ ) cisplatin was demonstrated to be effective at preventing and inhibiting cell proliferation during 48 hours. In a second experiment we performed a qualitative assay, demonstrating that active cisplatin could be released from the gel Vivostat-cisplatin. Necrosis of the mesothelioma cells could be microscopically observed, depending on the cisplatin concentration.

An effect of the cisplatin released from the gel on tumor growth was also qualitatively observed in the animal model in comparison with results seen in control animals in a preliminary experiment. Two animals were still alive 14 days after administration of cisplatin with the surgical carrier after pneumonectomy and tumor debulking, whereas in 2 control animals without administration of cisplatin, the tumor grew again, and the animals died after 10 and 11 days, respectively.

\section{Surgical Carrier of Cisplatin}

Vivostat (Vivolution) is a commercialized autologous surgical fibrin sealant that can be used to reduce the duration of air leak after lung resection or as an adjunct to hemostasis in cardiothoracic surgery. ${ }^{19-21}$ Fibrin was obtained from $120 \mathrm{~mL}$ of free frozen plasma (blood group 0 ) in a fully automated way, as described by Kjaergard and Trumbull. ${ }^{21}$ In our study a prototype of the classical Vivostat application system was used to allow the addition of the drug to the fibrin sealant. A system with 3 syringes was used: the drug syringe, which contained $1 \mathrm{~mL}$ of cisplatin; a syringe containing $1 \mathrm{~mL}$ of the $\mathrm{pH} 10$ buffer solution; and the fibrin syringe, which contained $2 \mathrm{~mL}$ of fibrin and $1.5 \mathrm{~mL}$ of cisplatin. With this composition and after autopriming, $1.5 \mathrm{~mL}$ of the obtained gel was necessary to change the color of the $\mathrm{pH}$ paper from blue to light green, indicating that the gel was suitable for application. The 4 $\mathrm{mL}$ of sealant, which was finally delivered to the animals with the Spraypen system (Vivolution), included $0.74 \mathrm{~mL}$ of buffer, 1.46 $\mathrm{mL}$ of fibrin, and $1.86 \mathrm{~mL}$ of cisplatin. A direct effect of the gel obtained from heterologous plasma 1 day and 1 week after application in the rat could be excluded by comparing histologic examination of the chest wall in control rats and in animals that received gel without cisplatin.

\section{Design of the Study}

Forty Fischer rats with a mean weight of $283 \mathrm{~g}$ (range, 254-300 g) were included in this experiment. The animals were kept in the rodent facility of the University Hospital Zurich under veterinary supervision before experiments. After removal from the rodent facility, animals were kept in designated rodent-storage modules in a temperature-controlled room on a schedule of 12 hours of light/12 hours of darkness and were fed standard rat chow and tap water ad libitum. At least a 1-week acclimation period was allowed before each experiment.

Implantation of the malignant mesothelioma cells at day 0 . General anesthesia was induced in an isoflurane chamber. Animals were intubated with a 16-gauge intravenous catheter and then connected to a volume-controlled ventilator (Harvard Rodent Ventilator, model 683, Harvard Apparatus Co Inc) and ventilated with oxygen-halothane at a tidal volume of $10 \mathrm{~mL} / \mathrm{kg}$ at 75 breaths $/ \mathrm{min}$ and a positive end-expiratory pressure of $3 \mathrm{~cm} \mathrm{H}_{2} 0$. The animals were placed in a right lateral decubitus position. After shaving and disinfection, a 2-cm lateral thoracic incision $1 \mathrm{~cm}$ caudal to the left shoulder joint followed by a sharp dissection through the cutaneous maximus muscle and identification of the ventral border of the latissimus dorsi muscle was performed. The muscle was retracted, revealing the intercostal muscles of the fifth intercostal space. The thin parietal pleural membrane was visualized, and $300 \mu \mathrm{L}$ of II-45 cell suspension ( 1 million cells) was injected with a 28 -gauge tuberculin needle without opening the pleural space. The wound was closed in 2 layers (muscles and skin) with interrupted sutures, and the animals were extubated. 
Application of cisplatin at day 10. After achievement of general anesthesia with intubation, a left lateral thoracotomy was performed in the fifth intercostal space (Figure E1). The left lung was mobilized by dividing the pulmonary ligament. The hilus was dissected, and left pneumonectomy was performed after preparation and successive application of clips on the pulmonary artery, the pulmonary vein, and the main bronchus. A tumor debulking consisting of the removal of most of the tumor nodules from the chest wall and from the mediastinum was performed, followed by a mechanical pleural abrasion with an abrader (electro-surgical tip cleaner, Surgisite, Johnson \& Johnson).

The 40 animals were randomly divided into 2 groups of 20 animals each according to the means of administration of cisplatin at a dose of $100 \mathrm{mg} / \mathrm{m}^{2}$ (or $3 \mathrm{mg} / \mathrm{kg}=1.85 \mathrm{~mL}$ of a solution of 10 $\mathrm{mg} / 20 \mathrm{~mL}$ of cisplatin in a 280 -g rat). In 20 animals $1.85 \mathrm{~mL}$ of cisplatin solution plus $2.15 \mathrm{~mL}$ of sodium chloride were delivered in the chest cavity, whereas in 20 animals cisplatin was mixed with fibrin obtained with the Vivostat system and topically applied as a gel, as described above (Figure E2). Because of the small volume of the chest cavity in this rat model, it was possible to completely visualize the pleura by means of a slight traction on the chest wall with the rib retractor and to apply the gel homogeneously in every part of the chest cavity. Thoracotomy was closed, as previously described, and the animals were extubated. Pain therapy included subcutaneous injection of $1.2 \mathrm{~mL}$ of paracetamol (Perfalgan, 10 $\mathrm{mg} / \mathrm{mL}$ solution) and buprenorphine (Temgesic) at a dosage of $0.1 \mathrm{mg} / \mathrm{kg}$.

Assessment of serum and tissue samples and death. In both groups of 20 animals, 5 subgroups of 4 animals each were defined according to the time interval between application of cisplatin and assessment of the samples ( 2 hours, 4 hours, 1 day, 3 days, and 1 week). At these different times, blood and tissue (chest wall and kidney) samples were harvested, and the animals were killed. Death occurred after achievement of general anesthesia by using a combined laparotomy and sternotomy. After harvesting of the blood samples and the kidneys, the animals were killed by means of section of the inferior vena cava, and the left chest wall was removed. Tissue samples were then collected under the microscope on the back table.

Blood samples. In each animal blood samples were harvested at day 0 before the injection of cells and at death. Blood was withdrawn in heparin-coated syringes. Laboratory findings included determination of hemoglobin, hematocrit, white blood cells, platelets, urea, and creatinine. A part of the sampled blood was centrifuged (3000 rpm for 8 minutes), and the serum was removed, divided in 3 tubes, and frozen at $-80^{\circ} \mathrm{C}$ for later platinum level determinations.

Tissue samples. At the time of death, the kidneys were harvested to evaluate the systemic toxicity of cisplatin according to the means of drug delivery. The kidneys were promptly fixed in $4 \%$ buffered formaldehyde. One half of the bisected kidney from each animal was embedded in paraffin. Two-micrometer-thick slides were prepared from the paraffin blocks and stained as follows: routine hematoxylin and eosin, periodic acid-Schiff (PAS), Säurefuchsin-Orange-G-Anilinblau, and silver. The pathologist was blinded to the animals and the type of treatment.

Tissue samples from the chest wall were collected on the back table. To avoid bias caused by the repartition of cisplatin in the chest, 3 samples of tissue were harvested at each time point from 3 predefined different locations (apical, mediastinal, and posterobasal) to provide better information about the drug level in the whole chest cavity. The 3 samples were homogenized and analyzed for determination of the drug level and the concentrationtime curve.

Determination of total platinum levels in serum and tissue samples. The level of total platinum was measured by means of inductively coupled plasma sector field mass spectrometric detection with a matrix-matched calibration procedure. ${ }^{22,23}$ The chemist was also blinded to the animal treatment.

\section{Statistical Analysis}

Statistical analysis was carried out with SPSS software, version 11.5. Comparison of variables before implantation of the mesothelioma cells and before harvesting in a group of animals at different times was performed by use of the paired $t$ test. A 2-sample or unpaired $t$ test was used to compare variables between the 2 groups of animals at different times. To address the problem of multiple comparison and because 5 comparisons were made in each case (at 2, 4, 24, and 72 hours and 1 week), we have considered $P$ values smaller than $.05 / 5=.01$ to be statistically significant (this is like performing a Bonferroni correction).

\section{Results}

In all the animals, recovery was uneventful after implantation of the malignant mesothelioma cells. Four animals could not be extubated after left pneumonectomy and died from cardiorespiratory insufficiency. One animal of the solution group was found dead in its cage 2 days after pneumonectomy and application of cisplatin. These 5 animals were replaced by other rats in which recovery was uneventful.

The analysis of the platinum concentration in the pleura showed a rapid increase of the measured values in both groups, with a maximum of about $1500 \mathrm{pg} / \mathrm{mg}$ reached after 4 hours. However, the platinum concentration rapidly decreased in the animals of the solution group between 4 hours and 1 day and then more slowly until 1 week. In the animals of the gel group, the concentration remained high between 4 hours and 1 day and then decreased slowly, but the concentration at 1 week was still 3 -fold higher than the minimal concentration of platinum required to produce necrosis of the mesothelioma cells in human subjects (1 $\mu \mathrm{mol} / \mathrm{L}=300 \mu \mathrm{g} / \mathrm{L})$. The concentration of platinum in the pleura was statistically different at 1 day, 3 days, and 1 week between the 2 groups $(P=.007, P=.005$, and $P=$ .0002 , respectively; 2-sample $t$ test; Table E1 and Figure 1).

The analysis of the platinum concentration in serum also showed a rapid initial increase in both groups of animals. The maximum was already reached after 2 hours in the solution group in comparison with that at 1 day in the gel group. There was no statistically significant difference in serum drug levels at any time between the 2 groups according to the mode of delivery (Table E2 and Figure 2). 


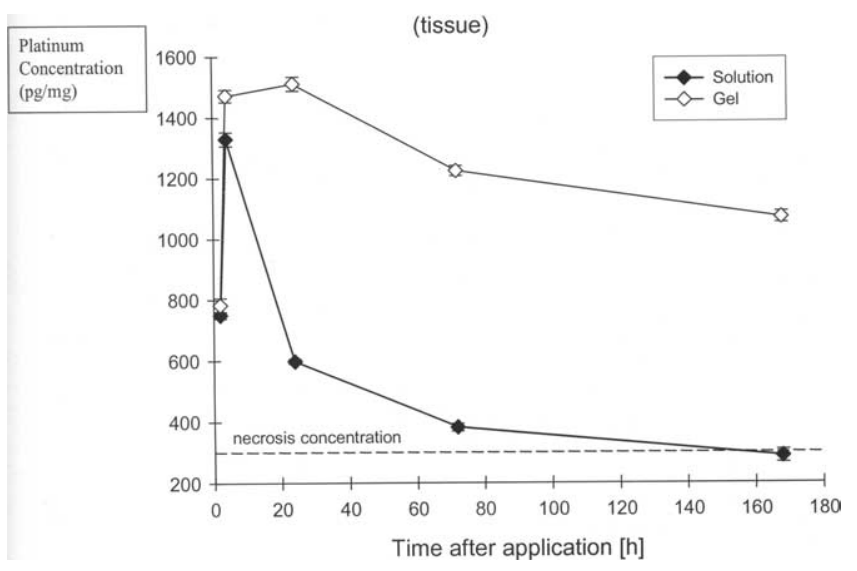

Figure 1. Platinum concentration in the tissue (chest wall) at different times after application in the chest cavity according to the mode of delivery.

At autopsy, the pleural fluid or the gel within the chest cavity was removed and assessed for determination of platinum concentration. In the solution group the concentration at 1 week could not be measured because the amount of fluid collected was not representative. The measured values in the solution group were $245.3 \mathrm{pg} / \mu \mathrm{L}$ at 4 hours, 132.2 $\mathrm{pg} / \mu \mathrm{L}$ at 1 day, and $79.2 \mathrm{pg} / \mu \mathrm{L}$ at 3 days, whereas the values in the gel group were 639.7, 401.6, 229.6, 126, and $118.6 \mathrm{pg} / \mu \mathrm{L}$ at 2 hours, 4 hours, 1 day, 3 days, and 1 week, respectively.

Laboratory findings showed signs of systemic toxicity at 1 week in the cisplatin solution group, with a significant decrease in thrombocyte numbers and renal insufficiency, whereas no signs of toxicity were observed in the gel group (Table E3). These results were also confirmed when comparing the different laboratory parameters between the 2

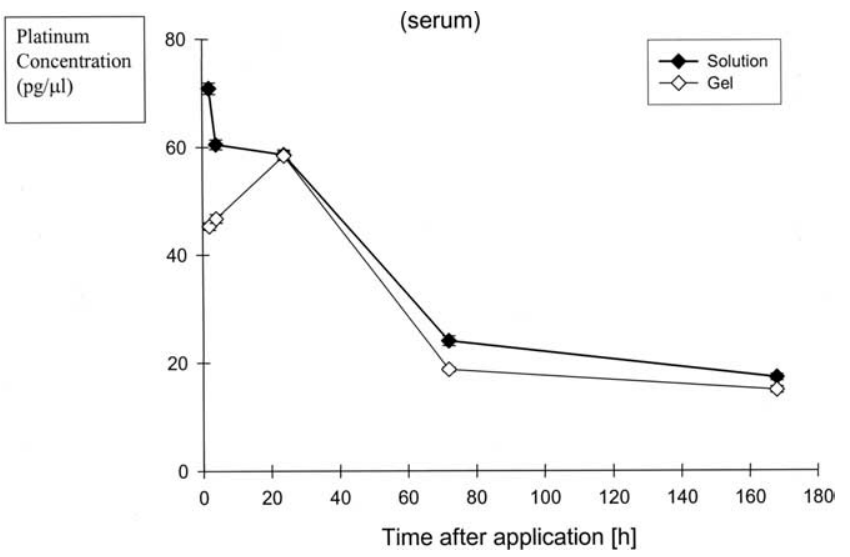

Figure 2. Platinum concentration in the serum at different times after application in the chest cavity according to the mode of delivery. groups of animals before harvesting at different times (Table 1). No difference in the measured hemoglobin levels, hematocrit levels, and leukocyte counts between the 2 groups at any time was seen.

Pathologic examination confirmed the results of the laboratory tests, showing an extended acute tubular necrosis of $50 \%$ to $60 \%$ of the examined area only in the animals of the solution group at 1 week and partially at 3 days, whereas the extension of the necrosis was limited (5\%) in all the animals of the gel group (Table E4). In the animals with extended tubular necrosis, the tubules were dilated and contained detached necrotic cells in the lumina. There was only a residual brush border visible in the PAS stain. Arteries and arterioles also exhibited vacuolization of the muscle layer. Peritubular capillaries were congested (Figure E3).

No difference was seen in the histopathologic examination of the kidneys in the other animals between the 2 groups. The examination showed focal signs $(<10 \%$ of the examined surface) of osmotic nephrosis in all the animals of both groups at 4 hours and in 1 and 2 animals of the solution group and the gel group, respectively, at 1 day. The subcortical tubules exhibited intracytoplasmic vacuoles, and the brush border was intact or fragmented in the PAS stain. The vessels, particularly the peritubular capillaries, displayed hyperemia and appeared congested (Figure E4).

\section{Discussion}

The therapy of malignant pleural mesothelioma is still under evaluation. The first multimodal concept, including extrapleural pneumonectomy followed by chemotherapy and radiotherapy in selected patients with the earlier stages of disease, showed a median survival time of 19 months. ${ }^{4}$ Our group initiated a new multimodality therapy concept, combining neoadjuvant chemotherapy with extrapleural pneumonectomy and postoperative consolidating radiotherapy. ${ }^{1}$ The results of this trial were promising, and a median survival time of 23 months could be observed with this combined approach. ${ }^{1}$ However, although consolidating radiotherapy was not uniformly performed in this series of patients, local tumor relapse was common, confirming the observations of the largest previous reports. ${ }^{24-27}$

TABLE 1. Comparison of the laboratory tests ( $P$ values) between the 2 groups of animals before harvesting at different times

\begin{tabular}{llllll}
\hline & $\mathbf{2 ~ h}$ & $\mathbf{4 ~ h}$ & $\mathbf{1 ~ d}$ & $\mathbf{3 ~ d}$ & $\mathbf{1 ~ w k}$ \\
\hline Hemoglobin & .6 & .04 & .4 & .6 & .2 \\
Hematocrit & .4 & .02 & .06 & .5 & .6 \\
Leukocytes & .4 & .8 & .05 & .9 & .06 \\
Thrombocytes & .01 & .1 & .08 & .4 & .01 \\
Urea & .5 & .1 & .004 & .8 & .02 \\
Creatinine & .8 & .4 & .01 & .9 & .01 \\
\hline
\end{tabular}


Several studies evaluating local application of chemotherapeutic agents in the pleural cavity showed that higher concentrations of the drugs in the tissue could be obtained, but these high concentrations could not be maintained long enough to markedly modify the course of the disease. ${ }^{5,7,15}$ In our study we decided to deliver a topical form of cisplatin in the chest cavity and to compare the pharmacokinetic profile of this administration with that of the previously tested approach with cisplatin solution. Cisplatin was mixed with the autologous fibrin sealant Vivostat and delivered as a gel. The advantages of the Vivostat system consisted of a fully automated preparation process conferring a good reliability of method and the possibility of delivering uniformly and homogeneously the gel obtained by use of an application Spraypen in each part of the chest cavity. Additionally, the Vivostat system overcomes the potential infective and antigenic risks associated with the use of most currently available fibrin sealant and has no known adverse events. ${ }^{19-21}$

Our results could confirm the observations of the previous reports, showing a rapid decrease of the platinum concentration in tissue only a few hours after application in the solution group. ${ }^{5}$ A very important finding was not only that the drug concentration in tissue was 3.7-fold higher in the gel group than in the solution group at 1 week but also that this concentration of $1069 \mathrm{pg} / \mu \mathrm{L}$ was still higher than the minimal concentration of platinum active on mesothelioma cells in human subjects.

Although no statistical difference was observed in the measured concentrations in sera between the 2 groups, laboratory findings demonstrated signs of systemic toxicity at 1 week in the animals that received cisplatin solution regarding thrombocytopenia and renal insufficiency. A possible explanation might be that the peak of serum concentration in the solution group was reached earlier than at the first harvesting time considered in our study (2 hours). Indeed, Rusch and colleagues ${ }^{5}$ demonstrated that systemic absorption was rapid after intrapleural administration of cisplatin solution, with peak serum levels being reached within 1 hour of administration of intrapleural chemotherapy. The early and rapid systemic absorption of cisplatin solution might explain the nephrotoxicity at 1 week because a delay of several days up to 1 week has already been observed until the apparition of the nephrotoxicity in patients who received an intravenous dose of $50 \mathrm{mg} / \mathrm{m}^{2}$ without prehydration. ${ }^{16}$

Several previous reports in patients showed that intravenous or local delivery of $100 \mathrm{mg} / \mathrm{m}^{2}$ cisplatin was associated with an acceptable toxicity. ${ }^{5,8}$ Side effects were mainly gastroenterologic (nausea and vomiting, $30 \%$ to $40 \%$ of the patients) and hematologic. Neuropathy and ototoxicity were seldom observed after intrapleural application, and almost entirely grade 1 nephrotoxicity was observed. Hanada and coworkers ${ }^{16}$ showed that blood urea levels 5 days after intravenous cisplatin application were the best indicator of nephrotoxicity. Investigations in a rat model revealed that nephrotoxicity after injection of 1 to $5 \mathrm{mg} / \mathrm{kg}$ or infusion of 5 to 25 $\mathrm{mg} / \mathrm{kg}$ was ameliorated after intermittent bolus injection and continuous infusion (over 2 and 3 hours). ${ }^{13,28}$

In our project the delivered dose of $100 \mathrm{mg} / \mathrm{m}^{2}$ cisplatin corresponded to $3 \mathrm{mg} / \mathrm{kg}$. Therefore nephrotoxicity of the procedure was expected to remain low. However, histopathologic examination of the kidneys confirmed the laboratory findings and the direct renal toxicity of cisplatin at 1 week in the group solution, with an extended tubular necrosis up to $60 \%$. Hofstra and associates ${ }^{14}$ showed that the dose in patients could be escalated to 270 $\mathrm{mg} / \mathrm{m}^{2}$ in local application (solution) and that dose-limiting toxicity was myelosuppression. As a consequence, it is reasonable to think that the topical application of higher concentrations of cisplatin with the surgical carrier Vivostat in human subjects might result in higher local concentrations in the tissue while conferring an acceptable low toxicity, which might be an advantage in comparison with other modes of local therapy. Additionally, the activity of the radiosensitizer cisplatin on residual mesothelioma cells might be increased by the postoperative irradiation of the operated thorax.

The transient increase of hemoglobin and hematocrit levels at 1 day in both groups might be due to a relative inactivity of the animals after the operation with reduced drinking despite pain therapy.

The animal model used in this study has already been described. ${ }^{17}$ Although several subcutaneous, intraperitoneal, and intrapleural animal models for malignant mesothelioma with xenografted human mesothelioma cell lines have been reported previously, these models do not represent the clinically relevant situation of pleural-based disease in an animal with an intact immune system. ${ }^{18}$ The approach described in this project has advantages over previously described models in that it closely resembles the histologic appearance of pleural disease in human subjects, allows for the study of the immune response and immunotherapeutic modalities, enables precise quantification of tumor mass, and is highly reproducible, with untreated animals dying within a month. ${ }^{17}$ However, a complete and precise pleurectomy was technically impossible because of the absence of an adequate layer between the pleura and the chest wall. As a consequence and to mimic the classical pleuropneumonectomy in patients, we performed a mechanical pleural abrasion after tumor debulking.

We are well aware that the number of animals in each subgroup was relatively small. However, because of the fact that (1) the Bonferroni correction was applied to address the problem of multiple comparisons, (2) the animal model was highly reproducible, (3) the pathologist and the chemist were 
blinded to the animal treatment, (4) the tissue samples were harvested in a standardized manner at 3 predefined locations, (5) the concentrations of platinum in the tissue were determined twice in each animal for each harvesting time, and (6) the histopathologic examination confirmed the results of the laboratory findings, we think that our results are highly accurate.

In conclusion, our results demonstrated a significant local pharmacologic advantage up to 1 week after administration of a topical form of cisplatin with the surgical carrier Vivostat in comparison with cisplatin solution, without increasing systemic toxicity in an immune-competent rat model. On the basis of these results, the administration of higher doses of cisplatin or of other radiosensitizers with this technique might be evaluated in several promising multimodality therapy strategies in experimental settings, and phase I clinical trials might be initiated. We plan to analyze the activity of the cisplatin released from the gel on the tumor cells by use of a recurrence model in the near future. We have already established a reproducible recurrence model with the same animal in which just such a nodule of tumor can be initiated. The effect of different doses of cisplatin on response, animal survival, and systemic toxicity will be assessed. In the next experiment the effects of a combination therapy consisting of the topical application of cisplatin and local radiotherapy will be evaluated.

D. Lardinois contributed to conception and design of the study, the surgical part, the collection and assembly of data, the data analysis and interpretation, the manuscript writing and supervision, and obtainment of funding support. F. J. Jung led the surgical part of the study. I. Opitz contributed to the surgical part of the study and the collection and assembly of data. K. Rentsch contributed to the determination of platinum concentrations in serum and tissue samples, to the laboratory analysis, and to the manuscript writing. D. Günther and C. Latkoczy performed the measurement of platinum in serum and tissue and took part in the manuscript writing. V. Vuong performed the culture of the mesothelioma cells. Z. Varga performed the histopathologic analysis. V. Rousson contributed to the statistical analysis. S. Bodis and R. Stahel contributed to the manuscript writing. W. Weder was the senior author of the study, initiated its conception, and contributed to the interpretation of the data and the manuscript writing.

We thank Regula Rüegg, Martin Pruschy, and Daniel Demierre for technical assistance.

\section{References}

1. Weder W, Kestenholz P, Taverna C, et al. Neoadjuvant chemotherapy followed by extrapleural pneumonectomy in malignant pleural mesothelioma. J Clin Oncol. 2004;22:3451-7.

2. Sterman DH, Kaiser LR, Albelda SM. Advances in the treatment of malignant pleural mesothelioma. Chest. 1999;116:504-20.
3. Sugarbaker DJ, Garcia JP. Multimodality therapy for malignant pleural mesothelioma. Chest. 1997;112:272-5.

4. Sugarbaker DJ, Mentzer SJ, Decamp M, Lynch TO, Strauss GM. Extrapleural pneumonectomy in the setting of a multimodality approach to malignant mesothelioma. Chest. 1993;103:377-81.

5. Rusch V, Niedzwiecki D, Tao Y, Markman M. Intrapleural cisplatin and mitomycin for malignant mesothelioma following pleurectomy: pharmacokinetic studies. J Clin Oncol. 1992;10:1001-6.

6. Vogelzang NJ, Rusthoven JJ, Symanowski J, et al. Phase II study of pemetrexed in combination with cisplatin versus cisplatin alone in patients with malignant pleural mesothelioma. J Clin Oncol. 2003;21: 2636-44.

7. Ratto GB, Civalleri D, Esposito M, Vannozzi MO. Pleural space perfusion with cisplatin in the multimodality treatment of malignan mesothelioma: a feasibility and pharmacokinetic study. J Thorac Cardiovasc Surg. 1999;117:759-65.

8. Sauter ER, Langer C, Coia LR, Goldberg M, Keller SM. Optimal management of malignant mesothelioma after subtotal pleurectomy: revising the role of intrapleural chemotherapy and postoperative radiation. J Surg Oncol. 1995;60:100-5.

9. Rusch V, Saltz L, Venkatraman E, et al. A phase II trial of pleurectomy/decortication followed by intrapleural and systemic chemotherapy for malignant pleural mesothelioma. J Clin Oncol. 1994; 12:1156-63.

10. Ong ST, Vogelzang NJ. Chemotherapy in malignant pleural mesothelioma: a review. J Clin Oncol. 1996;14:1007-17.

11. Nowak AK, Byrne MJ, Williamson R, et al. A multicenter phase II study of cisplatin and gemcitabine for malignant mesothelioma. $\mathrm{Br} \mathrm{J}$ Cancer. 2002;87:491-6.

12. Favaretto AG, Aversa SML, Paccagnella A, et al. Gemcitabine combined with carboplatin in patients with malignant pleural mesothelioma: a multicentric phase II study. Cancer. 2003;97:2791-7.

13. Pretorius RG, Eisenkop S, Lagasse LD. Utilization of a murine model to optimize volume and dwell time of intraperitoneal cisplatin. $G y$ necol Oncol. 1989;34:66-9.

14. Hofstra LS, de Vries EGE, Mulder NH, Willemse PHB. Intraperitoneal chemotherapy in ovarian cancer. Cancer Treat Rev. 2000; 26:133-43.

15. Lerza R, Esposito M, Vannozzi M, Bottino GB, Bugliolo G. Intrapleural cisplatin in mesothelioma. Cancer. 1994;73:79-84.

16. Hanada K, Ninomiya K, Ogata H. Pharmacokinetics and toxicodynamics of cisplatin and its metabolites in rats: relationship between renal handling and nephrotoxicity of cisplatin. $J$ Pharm Pharmacol. 2000;52:1345-53.

17. Kucharczuk JC, Elshami AA, Zhang HB, Kaiser LR. Pleural-based mesothelioma in immune competent rats: a model to study adenoviral gene transfer. Ann Thorac Surg. 1995;60:593-8.

18. Prewitt TW, Lubensky IA, Pogrebniak HW, Pass HI. Orthotopic implantation of mesothelioma in the pneumonectomized immunedeficient rat: a model for innovative therapies. Int J Cancer. 1993;55: 877-80.

19. Belboul A, Dernevik L, Aljassim O, Skrbic B, Radberg G, Roberts D. The effect of autologous fibrin sealant (Vivostat) on morbidity after pulmonary lobectomy: a prospective randomized, blinded study. Eur J Cardiothorac Surg. 2004;26:1187-91.

20. Kjaergard HK, Pedersen JH, Krasnik M, Weis-Fogh US, Fleron H, Griffin HE. Prevention of air leakage by spraying Vivostat fibrin sealant after lung resection in pigs. Chest. 2000;117:1124-7.

21. Kjaergard HK, Trumbull HR. Vivostat system autologous fibrin sealant: preliminary study in elective coronary bypass grafting. Ann Thorac Surg. 1998;66:482-6.

22. Zimmermann S, Menzel CM, Berner Z, et al. Trace analysis of platinum in biological samples: a comparison between sector field ICP-MS and adsorptive cathodic stripping voltammetry following different digestion procedures. Anal Chim Acta. 2001;439:203-9.

23. Bettinelli M. ICP-MS determination of $\mathrm{Pt}$ in biological fluids of patients treated with antitumor agents: evaluation of analytical uncertainty. Microchem J. 2005;79:357-65.

24. Sugarbaker DJ, Flores RM, Jaklitsch MT, et al. Resection margins, extrapleural nodal status, and cell type determine postoperative longterm survival in trimodality therapy of malignant pleural me- 
sothelioma: results in 183 patients. J Thorac Cardiovasc Surg. 1999; 117:54-63.

25. Maggi G, Casadio C, Cianci R, Rena O, Ruffini E. Trimodality management of malignant pleural mesothelioma. Eur J Cardiothorac Surg. 2001;19:346-50.

26. Taverna C, Stahel R, Bodis S. Malignant pleural mesothelioma: trimodality therapy at a single center. Ann Oncol. 2000;11:123.
27. Baldini EH, Recht A, Strauss GM, DeCamp MM, Swanson SJ. Patterns of failure after trimodality therapy for malignant pleural mesothelioma. Ann Thorac Surg. 1997;63:334-8.

28. Nagai N, Kinoshita M, Ogata H, et al. Relationship between pharmacokinetics of unchanged cisplatin and nephrotoxicity after intravenous infusions of cisplatin to cancer patients. Cancer Chemother Pharmacol. 1996;39:131-7. 
TABLE E1. Platinum concentration in the tissue (chest wall) at different times after application in the chest cavity according to the mode of delivery (mean values \pm standard deviation)

\begin{tabular}{lccc}
\hline & Solution $\mathbf{( p g} / \mathbf{m g})$ & Gel $\mathbf{p g} / \mathbf{m g})$ & $\boldsymbol{P}$ value \\
\hline $2 \mathrm{~h}$ & $749.9 \pm 11.3$ & $782.6 \pm 23.3$ & .4 \\
$4 \mathrm{~h}$ & $1392.1 \pm 22.9$ & $1471.3 \pm 20$ & .82 \\
$1 \mathrm{~d}$ & $597.7 \pm 8.2$ & $1510.5 \pm 23.2$ & .007 \\
$3 \mathrm{~d}$ & $382.0 \pm 12.4$ & $1223.5 \pm 16.7$ & .005 \\
$1 \mathrm{wk}$ & $286.5 \pm 21.3$ & $1069.0 \pm 18.8$ & .0002 \\
\hline
\end{tabular}

TABLE E2. Platinum concentration in the serum at different times after application in the chest cavity according to the mode of delivery (mean values \pm standard deviation)

\begin{tabular}{lccc}
\hline & Solution $(\mathbf{p g} / \boldsymbol{\mu L})$ & Gel $(\mathbf{p g} / \boldsymbol{\mu L})$ & $\boldsymbol{P}$ value \\
\hline $2 \mathrm{~h}$ & $70.9 \pm 1.05$ & $45.3 \pm 0.7$ & .11 \\
$4 \mathrm{~h}$ & $60.5 \pm 0.9$ & $46.7 \pm 0.8$ & .11 \\
$1 \mathrm{~d}$ & $58.6 \pm 0.9$ & $58.4 \pm 0.8$ & .98 \\
$3 \mathrm{~d}$ & $24.0 \pm 0.9$ & $18.7 \pm 0.4$ & .05 \\
$1 \mathrm{wk}$ & $17.2 \pm 0.6$ & $14.9 \pm 0.6$ & .43 \\
\hline
\end{tabular}


TABLE E3. Comparison of the laboratory tests (expressed as a mean value) before implantation of the cells and before harvesting at different times in each group of animals (paired $t$ test)

\begin{tabular}{|c|c|c|c|c|c|c|}
\hline & \multicolumn{3}{|c|}{ Solution } & \multicolumn{3}{|c|}{ Gel } \\
\hline & Before implantation & Harvesting & $P$ value & Before implantation & Harvesting & $P$ value \\
\hline \multicolumn{7}{|c|}{ Hemoglobin $(\mathrm{g} / \mathrm{dL})$} \\
\hline $2 \mathrm{~h}$ & 11.5 & 11.2 & .7 & 11.8 & 11.5 & .4 \\
\hline $4 \mathrm{~h}$ & 12.1 & 12.1 & .9 & 10.9 & 13.2 & .009 \\
\hline $1 \mathrm{~d}$ & 11.5 & 13.3 & .03 & 11.5 & 13.7 & .02 \\
\hline $3 d$ & 11.9 & 9.2 & .2 & 10.7 & 9.8 & .7 \\
\hline $1 \mathrm{wk}$ & 12.6 & 11.4 & .4 & 12.7 & 10.3 & .006 \\
\hline \multicolumn{7}{|c|}{ Hematocrit (\%) } \\
\hline $2 \mathrm{~h}$ & 34.8 & 33.6 & .3 & 36.6 & 35.9 & 6 \\
\hline $4 \mathrm{~h}$ & 35.7 & 35.7 & .5 & 32.6 & 40.9 & .005 \\
\hline $1 \mathrm{~d}$ & 33.4 & 38.2 & .01 & 34.4 & 42.5 & .03 \\
\hline $3 d$ & 34.6 & 26.9 & .2 & 34.4 & 29 & .2 \\
\hline $1 \mathrm{wk}$ & 36.4 & 31.3 & .2 & 37.5 & 30.2 & .004 \\
\hline \multicolumn{7}{|c|}{ Leukocytes $\left(10^{3} / \mu \mathrm{L}\right)$} \\
\hline $2 \mathrm{~h}$ & 6.3 & 6.9 & .5 & 5.8 & 6.4 & .04 \\
\hline $4 \mathrm{~h}$ & 7.7 & 6.6 & .6 & 5.6 & 6.2 & .6 \\
\hline $1 \mathrm{~d}$ & 5.8 & 4.2 & .1 & 7.7 & 6.3 & .1 \\
\hline $3 d$ & 6.0 & 5.7 & .7 & 5.7 & 5.7 & .9 \\
\hline $1 \mathrm{wk}$ & 4.7 & 10.1 & .06 & 7.3 & 10.1 & .007 \\
\hline \multicolumn{7}{|c|}{ Thrombocytes $\left(10^{3} / \mu \mathrm{L}\right)$} \\
\hline $2 \mathrm{~h}$ & 598 & 575 & .4 & 647 & 632 & .07 \\
\hline $4 \mathrm{~h}$ & 578 & 549 & .6 & 568 & 687 & .07 \\
\hline $1 \mathrm{~d}$ & 624 & 502 & .08 & 554 & 540 & .7 \\
\hline $3 d$ & 524 & 409 & .3 & 540 & 533 & .9 \\
\hline $1 \mathrm{wk}$ & 632 & 323 & .005 & 724 & 621 & .02 \\
\hline \multicolumn{7}{|c|}{ Urea (mmol/L) } \\
\hline $2 \mathrm{~h}$ & 5.9 & 8.67 & .06 & 4.8 & 7.9 & .08 \\
\hline $4 \mathrm{~h}$ & 6.2 & 7.4 & .06 & 5.8 & 10.1 & .1 \\
\hline $1 \mathrm{~d}$ & 5.6 & 20.2 & .02 & 5.1 & 5.4 & .6 \\
\hline $3 d$ & 5 & 22.4 & .02 & 5.2 & 8.5 & .1 \\
\hline $1 \mathrm{wk}$ & 5.7 & 98.2 & .01 & 5.5 & 7.7 & .6 \\
\hline \multicolumn{7}{|c|}{ Creatinine $(\mu \mathrm{mol} / \mathrm{L})$} \\
\hline $2 \mathrm{~h}$ & 45.5 & 54.5 & .6 & 37.3 & 57 & .07 \\
\hline $4 \mathrm{~h}$ & 41.3 & 52.8 & .08 & 40.8 & 50.3 & .09 \\
\hline $1 \mathrm{~d}$ & 42.5 & 58.9 & .05 & 38.3 & 41.7 & .7 \\
\hline $3 d$ & 36 & 69 & .1 & 38.3 & 42.8 & .1 \\
\hline $1 \mathrm{wk}$ & 39.3 & 409.8 & .01 & 39.4 & 43 & .8 \\
\hline
\end{tabular}

TABLE E4. Histopathologic examination showing the degree of tubular necrosis in the animals according to the mode of application of cisplatin

\begin{tabular}{llc}
\hline & \multicolumn{2}{c}{ No. of animals } \\
\cline { 2 - 3 } & Solution & Gel \\
\hline $5 \%$ & $3(1 \mathrm{~d})$ & $2(1 \mathrm{~d})$ \\
& 0 & $3(3 \mathrm{~d})$ \\
$10 \%$ & & $4(1 \mathrm{wk})$ \\
$20 \%$ & $1(3 \mathrm{~d})$ & $1(3 \mathrm{~d})$ \\
$50 \%-60 \%$ & $1(3 \mathrm{~d})$ & 0 \\
& $4(1 \mathrm{wk})$ & 0 \\
\hline
\end{tabular}




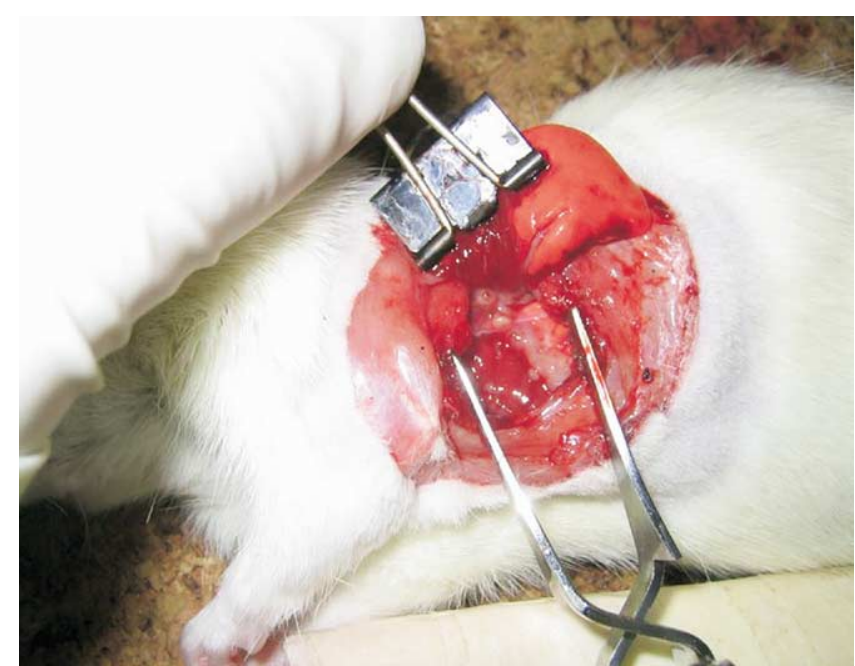

Figure E1. Intraoperative view 10 days after implantation of the mesothelioma cells showing the retracted left lung before pneumonectomy and the tumor nodules disseminated on the pericardium, the hilus, and the chest wall.

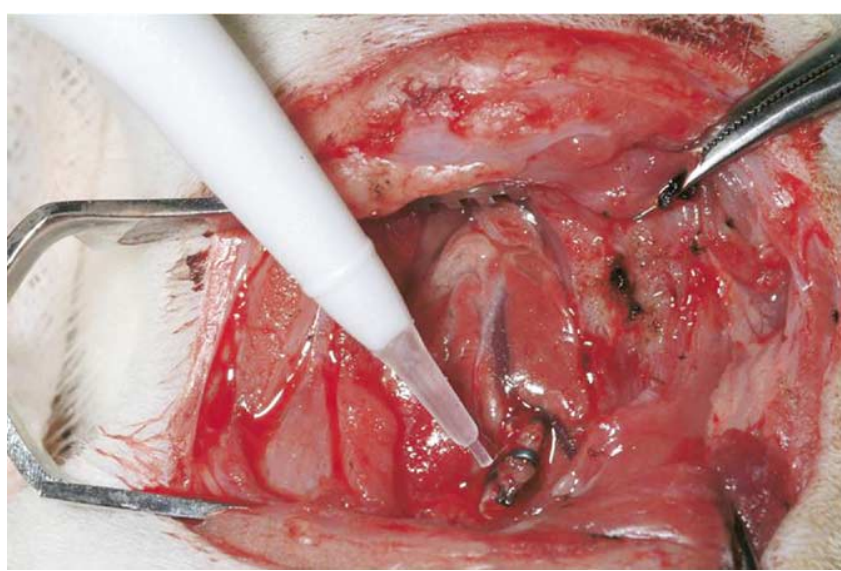

Figure E2. Intraoperative view showing the application of the gel cisplatin-fibrin sealant by use of the Spraypen with the Vivostat system after left pneumonectomy.

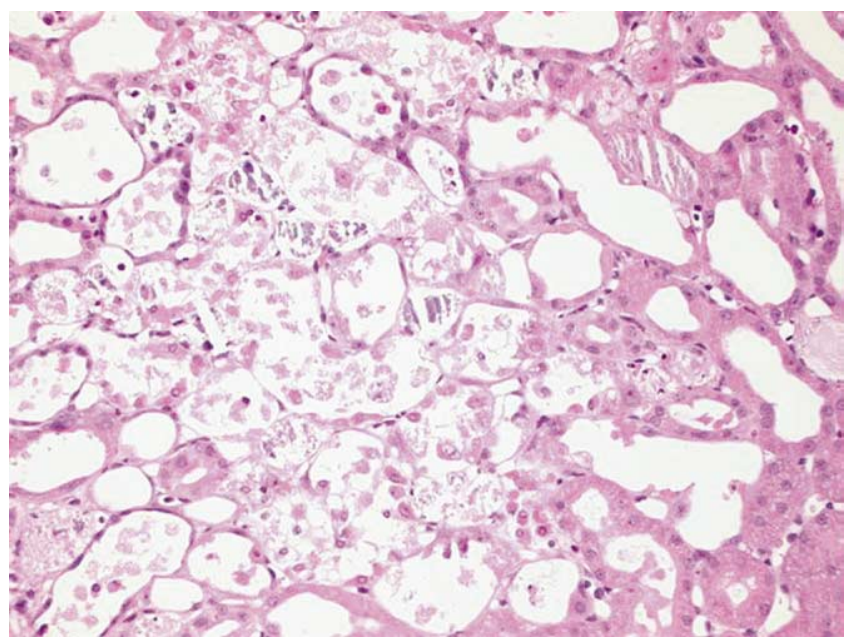

Figure E3. Extensive acute tubular necrosis. Dilated tubules with necrotic detached epithelial cells, as well intraluminal calcifications, are shown. (Hematoxylin and eosin stain, original magnification $400 \times$.)

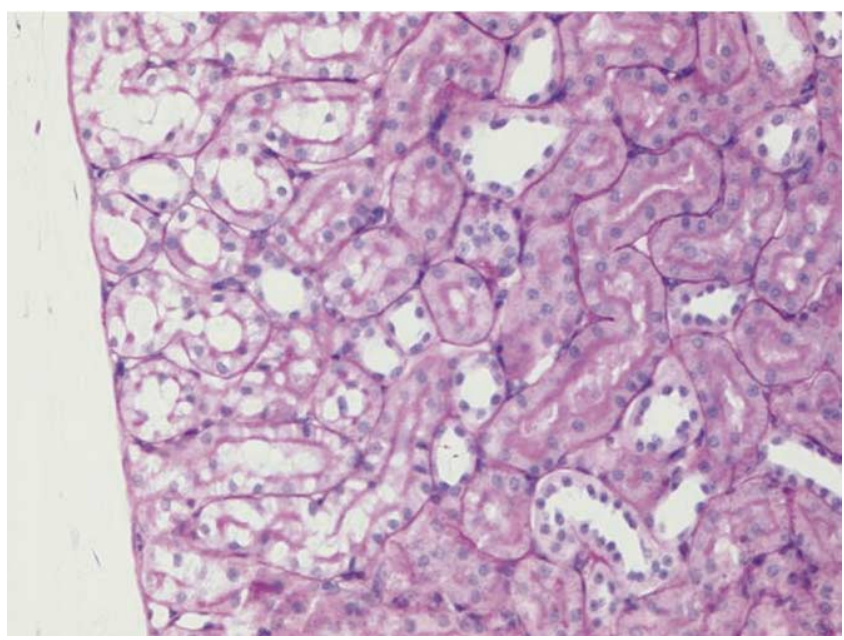

Figure E4. Cytoplasmic vacuolization of the subcortical tubules and fragmentation of brush border. (Periodic acid-Schiff stain, original magnification $400 \times$.) 